\title{
When does psychology drive culture?
}

\author{
Olivier Morin
}

Published in Edward Slingerland and Mark Collard eds. 20I I. Creating Consilience: Integrating Science And The Humanities, Cambridge: Oxford University Press, pp. I79-193.

Cultural epidemiologists such as Scott Atran, Pascal Boyer, Lawrence Hirschfeld and Dan Sperber, have developed an ambitious research program that focuses on the role of universal psychological constraints in the evolution of culture (Atran 2003; Boyer 2000; Sperber and Hirschfeld 2004). One of their main hypotheses is that cultural ideas or practices owe most of their success and stability in time and space to universal mechanisms of the human mind. Psychological constraints orient human minds when they learn, teach, remember, choose, endorse or transform all sorts of culturally transmitted information. As a result, cultural forms that fit these constraints tend to stabilize.

This view of culture seems unconvincing to many, and perhaps most, anthropologists or social scientists. They are, after all, specialists of human diversity; they do not necessarily see the point of studying universal features of our psychology - which are, by definition, the same in the vast majority of people. Many also doubt the importance of universal psychological features in the cultural decisions of individuals. This makes some sense. We all know that people often endorse an opinion or belief, choose to learn this or that technique, art or profession, not on the basis of their intrinsic appeal, but because of social pressure, material incentives, and such like. These local, particular constraints are strong. If general psychological constraints play any part at all, they seem to influence culture in a way that is both uniform and weak. When one is in the business of explaining contrasts between individuals or societies, this makes them twice irrelevant.

In this chapter, I want to argue that the impact of universal human psychology on culture is not everywhere the same. It is quite strong when a chain of cultural transmission is fed by a vast number of different 
individuals, less strong when fewer people are directly involved in feeding the chain (which happens if the chain is short, or long but fed by a small number of individuals). This impact will vary greatly in strength and scope: it is not uniform. It makes sense to take it into account, not only in the search for human universals, but also when trying to explain contrasts between different forms of cultural transmission.

The chapter begins with a short presentation of cultural epidemiology, and presents three cases in which universal cognitive constraints have been claimed to sustain a tradition-the tradition of etiquette rules in Europe, the representations of adalo spirits among the Kwaios, and the tradition of games of contamination ("cooties" in the USA) in children of many different countries. We shall look for the circumstances that make it possible for universal psychological constraints to prevail in these three cases. Then we shall see how the chances of success of universally appealing cultural items can be made to vary, by changing the size and shape of cultural transmission networks. In so doing, we can give universal psychological constraints a variable role in driving culture.

\section{Cultural epidemiologists at work}

Human minds shape culture in many ways, sometimes by producing it, sometimes by acquiring it, transforming it and diffusing around them modified versions of what they have learnt, sometimes by selectively acquiring certain things but not others. True, cultural learners are not always extremely selective. It has been argued that when we have to choose between cultural variants that are roughly indifferent, such as different first names for children or different dog breeds, we do not seem to show any bias whatsoever, except for choosing the variants we are most likely to be exposed to (Bentley et al. 2003). Still, no one claims that this is true of all things cultural. Even when cultural selection is weak or absent, human minds have other ways of shaping their culture: they produce and transform it in a non-random way.

Because of that, cultural epidemiologists think they can use psychological theories to make predictions regarding the fate of culturally transmitted ideas or practices. I will now give a sketch of the way they use psychological hypotheses, typically very general in scope, to explain cultural phenomena. I will describe three typical hypotheses and try to explain why, and in what conditions, they seem to work. I won't examine these hypotheses in an exhaustive way, nor defend them against any possible objection. I will merely highlight their potential interest and limits. 


\section{European etiquette norms}

- In one article on the evolution of social norms, Shaun Nichols (2002) makes a prediction concerning the history of European manners. Many etiquette norms (table manners, norms of posture, ways of behaving in polite society) seem arbitrary or even pointless; still, blind conservatism is not the only reason why they are preserved. A sizeable fraction of them owe their stability and success to the emotions that are elicited when they are broken, or when one imagines that they could be. Nichols believes, along with many psychologists, that some features of disgust ('core disgust') are well preserved across cultural boundaries. It is a well-established finding in psychology, Nichols remarks, that information eliciting strong emotions (disgust being one of them) is much easier to retrieve, especially on the longer term, than more neutral information. This, he speculates, may boost the long-term survival of disgust-eliciting norms, since a norm that stays longer in individual memories is more likely to be enforced and passed on.

He thus predicts that etiquette norms prohibiting actions that elicit 'core disgust' are more likely than others to be sustained and enforced, and less likely to be displaced. Inspired by Norbert Elias' work on the evolution of manners in Renaissance Europe (Elias 2000), Nichols examined the rules laid down in Erasmus' widely read guide, On Good Manners for Boys, and asked two groups of independent coders to state, for each rule (in several representative sections of the book) whether the conduct it prohibited could elicit 'core disgust', as defined by a checklist that was given them (first group of coders), and whether it was still parts of the rules of etiquette they were used to (second group of coders). The study found that most etiquette rules prohibiting some core-disgusting behavior made it to our own time, while most of those that did not failed to stay the course. While Elias argued that the slow rise of 'clean' manners in Europe was due to 'an expanding threshold of repugnance' (Elias in Nichols 2002: 20), Nichols claims that the 'threshold of repugnance' never moved one bit. Instead, etiquette manners slowly rose above the threshold, because human memory and cultural transmission promoted cleaner rules. 
- Children play games of tag almost everywhere, and in several countries and cultures, this game goes along with reference to some disease or pollution that is supposed to be transmitted along with the touch. Most of the time, the contagion takes the name of a disease or parasite, real or imaginary-like the Bokà (leprosy) in Madagascar (Sibree 1883), the British Lurgi (a fictitious disease-Opie and Opie 1959) and the American 'cooties' (a word also meaning lice and associated by many children with plague or leprosy-Hirschfeld 1997, Samuelson 1980). I heard from several sources that in the 1980s, the Paris suburbs saw a dreary epidemic of chat-sida ('AIDS-tag'). Typically (but not systematically) the contagion is feared well beyond the limits of the associated game of tag. Superstitions and prophylactic techniques to ward it off flourish. Sometimes (but not always) one or a few ill-fated children are said to concentrate all the pollution into themselves, and they are shunned accordingly. These features recur in a stunning variety of cultures, like India or Japan (Hirschfeld 1997; Haidt 2004).

According to cultural epidemiologist Lawrence Hirschfeld (1997), traditions like 'cooties' are stable and widespread among children because they recruit the same psychological mechanisms that are responsible for race and caste prejudices in adults. In his view, we are endowed with a specific cognitive device that detects social differences-differences in rank or group-membership-—and construes them as natural, biological properties of persons. Another hypothesis has been proposed by psychologist Jonathan Haidt (2004). He argues that games of contamination and the associated beliefs and practices appeal to a certain aspect of our faculties for moral reasoning. According to Haidt, moral psychology shares certain basic mechanisms with an emotion that first evolved for entirely non-moral reasons: disgust. According to Rozin and Haidt (Rozin, Haidt and MacCauley 2000), the most important adaptive function of disgust is to motivate us to avoid contamination by pathogens and infectious diseases (a hypothesis that explains several features of disgust, including the association principle', the privileged relation between disgust and meat or bodily excretions, etc.).

They also found that a fraction of our moral psychology makes heavy use of our disgust faculty. As a result, our intuitions on moral and social matters are often intermingled with judgments of disgust, and

\footnotetext{
I The association principle, as applied to disgust, predicts that people will show a disgust reaction towards any object that is linked with a disgusting object by a material association, however remote the association. For instance, people are disgusted by a glass of water in which one has dipped a 3 meters thread whose other end is dipped in a glass of urine. The association principle extended to moral disgust explains, for example, why many people would refuse to wear Mussolini's sweater, even if it had been washed a hundred times - Rozin and Nemeroff 1990.
} 
fears of contamination. Contamination games would appeal to such a mix of preoccupations with both sanitary and social "purity." Hirschfeld's theory and Haidt's are both very tentative, and some of their predictions differ. Yet, the fact that 'cooties' traditions are found in many different parts of the world where they appeared in an apparently independent way, makes it plausible to think that these traditions target some important and widespread cluster of dispositions concerning the fear of social and nonsocial contamination.

\section{Spirit Beliefs Among the Kwaio}

- Among the Kwaio who live in the mountainous center of Malaita Island (Solomon Islands), almost everyone claims to have interactions with ancestral spirits called adalo (Keesing 1982, 33-59). They can be met in dreams or prayed and sacrificed to, and divination yields information as to their intentions and ways of action-crucial information, since adalo are behind many significant events of daily life. When taro crops are bad, when someone falls ill, one will try and find out which adalo caused the trouble, and why; for adalo do not harm gratuitously: they use their omniscience to prevent, detect and punish all sorts of misdemeanors (Keesing 1982, 42). Relations with adalo are highly strategic since their intentions, however menacing, are seldom obvious. Apart from the way adalo get and use strategic information bearing on human perils and rewards, most Kwaio show very little interest in the properties of adalo, their nature or their place in the universe. Ideas become extremely vague when conversation drifts away from immediate strategic interaction with the spirits.

According to Pascal Boyer's interpretation of Roger Keesing's ethnography (Boyer 200I) belief in adalo (as happens with many other ghosts, spirits and ancestors) owes its stability to a universal human propensity to search for intelligent agency. Detecting intentional agents, the theory goes, is a crucial task for us, and evolution has given us a specific psychological faculty for that purpose. Given the importance and complexity of this task, and the costs of failing to detect intentional agency when it occurs, our intention-detection devices tend to get activated a little too readily. Still, when they do, we do not simply dismiss the signal as a false alert. Attributing an event to an intentional agent, real or not, authorizes many interesting inferences on strategic matters, like its dispositions towards us, its overall plans, its future actions, etc. The appeal of strategic information, combined with the ease of inferring it, can easily offset 
skepticism. Everything else being equal, a belief that allows us to make sense of events by appealing to a form of intentional agency will benefit from a favorable prejudice. Boyer signals, in support of his interpretation, the fact that it helps explain the way the Kwaio focus on strategic information, and more generally the lacunar character of representations of ghosts and spirits.

\section{When does cultural epidemiology work?}

Each one of these three studies relies on strong, speculative and debatable psychological hypotheses. My point here is not to discuss in detail the merits of their arguments. Instead, I would like to ask a question. Suppose these authors are right, and cultural things like adalo, 'cooties' or etiquette rules are successful and stable mostly because they appeal to universal properties of the human mind. Are these cases typical of cultural transmission in general? Or must some special conditions be met if we want cultural items to survive by means of their universal psychological effects? I think 'cooties'-lore, etiquette rules and adalo beliefs are indeed transmitted in special conditions--not weird, not uncommon, but special.

\section{Etiquette Norms}

- What makes cultural transmission special in the case of European norms of etiquette is indeed quite banal: if Nichols was able to measure the differential survival of Erasmus' prescriptions, that is because enough time had passed for many of them to die out. The fate of cultural habits is not so often measured at an interval of several centuries. Had Nichols carried out his experiment with European students a few years after Erasmus' book was published, the results would probably have been quite different. In particular, the impact of core disgust might have been harder to detect, as Erasmus' authority would have carried more weight. After all, On Good Manners for Boys was not just any manners guide. The Renaissance equivalent of a best-seller (130 editions, translated in four languages soon after its publication), it was written by one of Europe's first intellectual superstars. That is a triviality but, I hope to show, one with many consequences: selection, when it takes the form of differential survival, takes some time. On shorter timescales, the effect of people better remembering and transmitting disgust-related rules may be too noisy to be detectable. It may also be blurred by local accidents, like the influence of Erasmus. 


\section{Contamination Games}

- The traditions around games of contamination also depend on a special network of cultural transmission. Everyone who has written on the topic agrees that 'cooties'-lore and other contamination traditions are passed on from child to child, with little or no adult intermediation. They form part of children's very own peer-culture (Hirschfeld 1997; Opie and Opie 1959). Only one out of Sue Samuelson's forty-five informants had not first heard of 'cooties' through a peer (Samuelson 1980). Being handled down from child to child is a permanent challenge to the stability of children's peer cultures. Consider a population of children between six and twelve years old-a group of comrades at a primary school for instance. Let us define their peer-culture as including everything that is passed on between the children of the group, while they are between six and twelve years old. In this population, around one sixth of the children will be replaced every year. Every year the eldest children-probably the most knowledgeable about their peer-culture-will leave childhood and be replaced by a contingent of younger children. Six years later, there may not be a single child in the group to remember the group of six years ago.

This rate of population renewal is much higher than that of most human societies. It means that, if a tradition has lasted much longer than sixty years (as have many rhymes and games in children's peer cultures, including 'cooties'-lore-Samuelson 1980, Opie and Opie 1959) then, in our population of children, it has risked complete extinction ten times at the very least. Ten times, the population has been entirely renewed, with the risk, for each new generation, that it might not come into contact with the tradition. In a regular human society, where people of fifty can teach songs and games to children of five, a tradition can last sixty years and risk extinction only once. A fifty-year old woman can ensure a song a decent life expectancy by teaching it once to her son; in children's peer cultures that is not possible. If a child manages to transmit a song to her peers, she will buy it only a few years of survival. The vast majority of the participants in the peer-culture are beyond her reach: they are not yet born. When these new participants arrive in the culture, current children will not be children anymore. In these conditions, children's peer-transmitted games and rhymes have to be intuitive and attractive: in constantly shifting populations, their hyper-frequent transmission is a matter of survival. One might speculate that this is why the products of children's peer cultures are so catchy: boring rhymes simply died out. 
The comparative analysis of children's and adults' oral traditions by cognitive scientist David Rubin (1995) shows that memorization and transmission in children's peer culture obey particular constraints. I have argued elsewhere (Morin, 2010) that hyper-frequent transmission can explain other unusual properties of children's traditions, including their uniformity and the surprisingly high 'life-expectancy' enjoyed by some of them.

\section{Spirit Beliefs}

- The tradition surrounding adalo among the Kwaio is the trickiest case of all, because it is actually not that stable or successful. By Keesing's estimate, belief in ancestor spirits has been alive on Malaita for two millenia at least (Keesing 1982, 217-218). Yet it is no longer dominant. Traditionalist Kwaio are a small minority today; most islanders, many Kwaio included, have embraced Christianity and abandoned their small mountain settlements for larger settlements on the coast, dominated by the influence of Christian missionaries. Needless to say, cultural transmission on the coast favors a quite different kind of religion.

On the face of it, the Christian God does not seem more appealing to our intention-detectors than adalo. If anything, adalo have the upper hand: as we saw, they are almost stripped off of any feature that isn't related to their being intentional agents and ancestors. The Christian God does share some of the characteristics that make adalos interesting for an intention-detector, mostly concerned with strategic information. He too is an omniscient and vengeful spirit who watches upon us. Some other features of the Christian God, that come from a very local and particular tradition, are mind-boggling. For example, according to some missionaries, $\mathrm{He}$ is three things and one thing at the same time. It is difficult to construe that feature as attractive information for an intention-detector to feed on.

The missionaries have all means at hand to propagate a complex, and occasionally puzzling creed. The word they are spreading can afford to be unintuitive in some respects, because its stability does not depend so much on its being extremely easy to teach, store or recall: Christians have special, standardized institutions and technologies to do the teaching, the storing and the recalling. They do not have to rely on the mind of the faithful alone. In addition, the missionaries along the coast have spiritual 
authority over many people, whom they can teach by the hundreds; they can afford to lose some of them.

No such luck for beliefs about adalo: their transmission took place in conditions where nothing could make up for a lack of intuitive appeal. They survived the passing of generations for millenia, in a very sparse population, living in tiny, scattered settlements in the most rugged and mountainous sector of Malaita (Keesing 1982, 9-10 and 13). Transmission across space must have been difficult. So must have been transmission across generations. Here, Kwaio culture was confronted with the problem of cultural transmission across population renewals, with an additional complication: demographic scarcity. When groups are so tiny and scattered, some of them at some moments in time will lack entire demographic categories, like middle-aged women or old men (Keesing 1982, 17). As a result, some cultural forms that have to be passed on from one demographic category to another (e.g., elderly grandmother to adolescent daughter), because of some taboo, ritual necessity, or special interest in the other category, cannot be transmitted adequately. A fair proportion of Kwaio religious practices are subject to a transmission restriction of this kind (Keesing 1982, 198-202). The problem is all the more acute since, as Kwaio traditionalists know too well (Keesing 198I, 85 and 90), only a few members of a given demographic category will make good learners: not all youngsters with the appropriate background also happen to have the skill and dedication it takes to master the most complex forms of lore. Many Kwaio cultural practices must have been swallowed by such a demographic glut before they could reach the Kwaio of today. In these conditions, Kwaio traditions have had to travel lightly and efficiently: for things like belief in adalo, that means being reduced to their barest and most intuitive components.

\section{Cultural Transmission Chains}

What do our examples have in common? Etiquette norms, contamination games and traditions concerning adalo are all passed on through cultural transmission chains: chains linking different individuals, each of whom received a cultural item from someone else in the chain, and possibly passed it on to someone else. As cultural transmission chains, they have two special features in common. First, the individuals included in the transmission chain (all individuals reached by the tradition across space, or across time and generations) are numerous, in absolute terms: these chains are long. Second, no individual in the chain directly interacts 
with more than a small number of individuals (I do not mean absolutely small, but small compared to the overall number of individuals in the chain). As a result, no member of the chain can have more than a local impact upon cultural transmission, and the chain has to be fed by many people. Broadcasting is not possible on the scale of the whole chain: these chains are narrow ${ }^{2}$.

I think that there is a causal link between the length and narrowness of these chains and the fact that the traditions they carry appeal to universal features of the human mind. This suggests a conjecture: when transmission chains are shorter or broader, what will be passed down the chain depends on the choices of a smaller number of individuals. The smaller their number, the more likely they are to be guided by idiosyncratic or local preferences. When transmission chains are longer and narrower, however, many more individuals get to weigh upon the selection of traditions. Idiosyncratic or local preferences, being variable and inconsistent, will tend to cancel one another out, and only universally shared preferences will exert a consistent effect on the selection of cultural items.

Therefore, if universal psychological factors exert some pressure over the selection of traditions by individuals, then this pressure varies depending on the length and narrowness of transmission chains. In what follows, this conjecture will be fleshed out.

\section{Long and narrow chains of cultural transmission}

Universal psychological features are abstractions; no one is a universal human being. Many of our mental capacities and motivations are peculiar to ourselves: they are idiosyncratic, like my taste for whisky mixed with vinegar. Others, like the admiration many Republicans feel for Sarah Palin, are restricted to the members of a social group. These may be acquired culturally or not: Sarah Palin shares a taste for moose meat with French Canadians, because moose meat is easily accessible in their common environment. All these ideas and motivations can have an important impact on the cultural success of many things, like Balsamic-Whisky cocktails, moose-hunting techniques, or the endorsement of drilling projects in Alaska. I do

\footnotetext{
${ }^{2}$ Narrow transmission chains are not social networks with very low connectivity. When long, transmission chains may span many different societies and generations; some of these social groups will have high average connectivity, but not others. A transmission chain is not a society or several connected societies. It is the trajectory of an idea. A chain is narrow when the mimimum number of people that one has to go through, when one wants to spread an idea far and wide in space and time, is big, because no individual, well-connected though she could be, can directly reach most of the population of the chain--not necessarily for a lack of friends, but also because most of the population lives in in societies beyond her reach, or in times beyond her own. A chain can be narrow when everyone's connectivity is very high on average, as long as no single individual is so highly connected as to be able to reach most people in the chain directly. If, on the other hand, one single individual can reach everyone in the chain, the chain becomes broad even if average connectivity is very low.
} 
not intend to downplay the importance of these factors in determining individual cultural behaviors. I actually think that they are typically much stronger--that is to say, much better predictors of an individual's cultural behavior-than universal psychological constraints.

Yet, they lack two important features that universal psychological factors, however weak, have in common: consistency and reliability. Things like the bias for detecting intentions hypothesized by Pascal Boyer in his explanation of adalo beliefs, or the 'core disgust' emotional faculty used by Shaun Nichols, are supposed to be present in almost everyone (reliability) and, as far as their effects on cultural transmission are concerned, to weigh in the same direction in almost everyone (consistency). In contrast, one's admiration for Sarah Palin will influence the way one feels about drilling for oil in Alaska, but not in a reliable way (not everyone admires Sarah Palin) nor necessarily in a consistent way (Sarah Palin might change her mind about drilling in Alaska, which may change the position of her admirers). Without some consistency and reliability, even strong preferences cannot have perceptible effects on the scale of long, narrow chains of cultural transmission. On the contrary, when a factor contributes to the success of a tradition in a consistent and reliable way, its contribution does not need to be strong; it will prevail in long, narrow cultural chainschains of cultural transmission that include many people, none of these people passing on the tradition to more than a small proportion of other people in the chain.

The local or idiosyncratic factors that weigh upon individual cultural choices can have a huge influence on a cultural transmission chain, if it is short (i.e., if it includes only a small number of individuals ${ }^{3}$ ). This involves nothing more complicated than the Central Limit theorem of probability theory. If many people make a choice, and there is one reliable factor that consistently influences their choice in a given direction, then the more people you observe, the more chances you have that their cumulated decisions will reflect that factor: noisy factors will average out. On the other hand, when people are less numerous, noise (that is to say, unreliable factors weighing in inconsistent directions) is more likely to prevail.

\footnotetext{
${ }^{3}$ Long transmission chains are not long relatively to the number of people in a given social group. They are long in absolute terms: they include many, many people, from many different times and many different social group. If a group of twenty-five people all share the same cultural habit, and nobody else does, then the cultural transmission of that habit does not follow a long chain. It comprises $100 \%$ of a small group, but it does not extend in time to further or previous generations, and spans no other group. As a result, the cultural habit invented and maintained by these twenty-five persons are more likely to reflect their local and peculiar preferences than general features of the human mind.
} 
When the chain is long, local factors can still have an important effect upon it. But then it has to be broad (as opposed to narrow). It must allow one or a few individuals to broadcast their cultural preferences to an important proportion of members of the chain. These individuals being so few, their choices can reflect their local preferences as readily as universal ones. Broadness does not erase the influence of universal psychological factors in the choices of receivers. But it can skew it in two ways. First, the item chosen by the broadcasting minority is much more accessible to cultural learners than other (possibly more attractive) items. Second, the prestige and influence of the broadcasting minority can also orient the choices of cultural learners. That is how broadcasting, if carried on at the scale of a long transmission chain, can produce discrepancies between the success of a cultural item and its appeal to human psychology. We saw an example of that with the Kwaio: the cultural transmission chain of Christianity is much longer than that of adalo tradition (it includes many more people); still, relatively unintuitive beliefs like the Trinity can stay the course in that chain, because they can be imposed through institutional and technological methods of broadcasting.

Culture is not all about local influences (like the power of prestigious leaders) and idiosyncracies, nor is it just a matter of following universal psychological tendencies. Obviously, it is both--and it can be more of the first or more of the second, depending on the type of transmission chain you consider, and the scale at which you consider it. Suppose you want to cause a very long bridge to tumble down. Engineers say that there are two ways of doing so, one of them more cost-effective than the other. You can keep hitting the bridge with demolition engines at various points, without planning anything about the direction, location and pace of the shocks. Or you can apply a series of small shocks that will hit the bridge consistently, in the same direction, at a regular pace, and then wait for a wave of resonance to dislocate the bridge. That, of course, is the cost-effective way of destroying the bridge on all its length. But suppose you are interested merely in tearing down one short segment: in that case, the quick and dirty method of hitting it strongly at random might be just as efficient. It is all a question of scale. Depending on the scale, local influences will be magnified or blunted. Let us see one example of this.

At the end of the XVIlth century, the parish of Warbleton (Sussex, England) was hit by a strange new wave of Christian names (Fisher 1989, 96-97). The local Elizabeths, Marys and Abigails started to beget children with such names as Fight-The-Good-Fight-Of-Faith White, Kill-Sin Pemble, Humiliation Scratcher, or Mortifie Higgs. 
From 1570 to $1630,43 \%$ of Warbleton newborns received one of these so-called "hortatory names." Of course, the fad had religious origins. Hortatory names had long been a Puritan specialty, in Sussex and elsewhere (witness Harvard's Increase Mather). Yet, in Warbleton, this tradition was upheld with particular intensity by the local minister, Thomas Hely, whose four children were respectively christened Much-Mercye, Sin-denie, Increased and Fear-not (Caplan 1965). Obedience to religious standards conspired with Hely's authority to make hortatory names a must-have.

The Warbleton fad was atypical, even by Sussex standards. In East Anglia, less than four percent of Puritan children were given hortatory names. They were no more successful in Massachusets, Increase Mather notwithstanding. They would probably have been if more Puritans from Sussex had made the trip to New England, but very few did, whereas East Anglians emigrated en masse.

There probably were dozens of ministers like Thomas Hely across Puritan England and America, but their influence covered only a tiny portion of a vast cultural transmission chain. Hortatory names could not afford to skip a single step in that chain: they were vulnerable to cultural sampling accidents. Such an accident happened when Sussex Puritans decided to stay in England, while East Anglia opted for emigration. The Thomas Helys of that time also failed because, for every Thomas Hely who rooted for hortatory names, there was another preacher, elsewhere, who could argue against them. The influence of ministers reflected variable religious and onomastic preferences, that came and went in their own cycles of fashion. As far as hortatory names were concerned, these preferences pulled the faithful in variable, inconsistent directions. Their cumulated effect on the overall success of hortatory names amounted to little more than noise.

As Fly-Fornication Bull from Sussex discovered, to her discontent, when she was surprised in a compromising position with her neighbor, one Goodman Woodman (Fisher 1989, 97), hortatory names are vulnerable to ridicule. Many, like Fight-The-Good-Fight-Of-Faith, are unwieldy. Most do not carry information about the sex of their bearer. These are reliable handicaps: they do not depend upon religious fads or the decision of influent preachers. In long chains of cultural transmission, they outweigh such influences quite easily: large scales average out the effect of local preferences and express reliable and consistent factors. Had the chain of cultural transmission been shorter, or had Thomas Hely found a way of influencing many more people, these handicaps could have been suppressed--as they were in Warbleton from I570 to 1630. 


\section{How long and narrow can cultural transmission get?}

These considerations might seem quite trivial. Yet their potential impact on theories of cultural evolution is less trivial. Are humans so fascinated by the prestige of their leaders that they routinely and blindly endorse norms and habits under their influence, even if these fly in the face of basic human motivations (like our desire for survival and the care of our interests)? If so, how does the influence of leaders propagate through time? Are traditions stable enough, and populations varied enough, for the pressure of cognitive constraints to be felt? To answer this kind of question, we would need to know a lot about the shape and length of the communication networks that allow culture to spread. How long and narrow, can we expect cultural transmission chains to be? The question is far too general to admit of anything but vague answers, vulnerable to many qualifications. Still, in this last section, I want to take a shot at it. My conclusions will be, first, that we are very bad at assessing the length of transmission chains, and second, that when we can be sure that a transmission chain is long, then, given certain conditions, we can often assume that it is also narrow.

\section{I. How long?}

There are unambiguous proofs (from folklore, archeology, prehistory, comparative anthropology, cultural history, etc.) that long chains of cultural transmission exist-and we have seen several examples of this above. Yet in many cases, the information that we can acquire on the extension in space and time of a given cultural tradition, is surprisingly scarce. The very existence of cultural continuities in a society can be hotly debated. Among historians, it has become a commonplace (since Hosbawm and Ranger 1992) that the traditional character of most traditional practices is a pure invention. This is an exaggeration, but even so, its popularity shows how weak and defenseless claims of cultural continuity can sometimes be in the face of informed criticism. Most of the time, when we claim that something is culturally transmitted, we would be unable to make but the fuzziest estimations concerning its distribution. How long has it been around? Is it shared by everyone in this society? In other societies? If not, who has it? We are often still without reliable means of answering these basic questions. 
Today, the public is still persuaded that anthropologists study traditional societies, coherent cultures whose ways have been passed on from generation to generation. Many anthropologists, however, have all but given up on this hypothesis. For a start, many fieldworkers are simply unable to assess cultural continuity in the societies that they study. As Pascal Boyer $(1988,13)$ puts it, "ethnographers never observe traditions." Rather, they try to reconstruct them from multiple observations, relying on others to check the extension of the tradition in time and space. Still, in many cases, cultural continuity just isn't there to be found. One ethnographer finds that the most highly regarded Big Man on the island does not know the basic rites of a crucial potlatch ceremony, and begins to suspect that his own expertise in the local traditions goes well beyond that of his informants (Hocart 1927). Epics taken to epitomize an ancestral tradition turn out to be mostly improvised, with very little in the way of a common pattern (Boyer 1988). Bible students in a Pentecostal Church give stunningly variable accounts of classic tenets of their faith (such as the commandment "Thou shalt not kill" or the Golden Rule-Atran 200I). Such cases can be multiplied. Robert Aunger (1999) draws a convincing list of all the problems that plague claims of cultural consensus for a belief or a practice. The problem is not so much that cultural continuity is often weaker than expected; sometimes, we just don't know how to look for it.

One way of studying cultural transmission in a rigorous, quantitative way seems quite promising. The idea is to provoke chains of cultural transmission artificially, in a lab, with humans or other animals (Mesoudi and Whiten 2008; Whiten and Mesoudi 2008). There is much to learn from these experiments. Still, the transmission chains that they study are all extremely short (hardly ever more than 100 links); as a result, they tend to exaggerate the impact of transient, local influences on cultural transmission. For example, they overestimate the importance of our tendency to imitate arbitrary behaviors. Many such transmission chain experiments show that functionally indifferent behaviors - for example, opening a box in one way rather than another that is equally efficient - will be reproduced for several cultural generations. A behavior without any intrinsic interest is thus kept alive by arbitrary imitation alone. Yet all these experiments also show that indifferent behaviors disappear very rapidly: very few last more than a dozen transmission episodes. This is true even when conformity is extremely high, with more than $90 \%$ of individuals imitating the indifferent behavior (Claidière and Sperber, 2010). On the scale of real cultures outside the lab, these effects would be less than weak; they would not be visible at all. 


\subsection{How narrow?}

There is a link between the extension of a transmission chain in time and space, and its narrowness. Typically, when a chain extends in time and space, most of the individuals the chain includes will drift out of reach of others in the chain. We saw that happen in most of our examples. In the case of adalo, demographic scarcity, geographical scattering and the extension of the chain in time all concur to prevent religious 'broadcasting'. In children's peer cultures, demographic distance is to blame for narrowness: a child does not have access to most other children in the peer-culture, because most of them are not born, or are not children anymore.

So, are long cultural chains necessarily narrow? No. Members of long chains are not necessarily inaccessible to one another, because long cultural chains do not necessarily have vast extensions in time or space. Long cultural chains are just chains that include many people. The relation between their length and their extension in time and space is not straightforward. Imagine an archeologist deciphering a secret esoteric prayer written by a priest on the sarcophagus of a Pharaoh: this gives you a cultural transmission chain spanning several millenia, and including only two individuals. Today, several technologies allow one individual to get direct access to a huge variety of people, scattered in space or time. These chains are long, and broad. Still, the techniques that allow us to communicate across long distances in time (archeological investigations, writing, institutions like libraries, monuments, etc.) and space (regular and extensive travel to densely populated places, institutions for scientific or religious propagation, mass-reproduced writing, TV, etc.) are all quite recent in human evolution, and their influence can be ruled out in many cases. In many societies, there is simply no way for one individual to visit a vast number of people across distances of centuries and hundreds of kilometers. As a result, the proportion of individuals that each person in the chain can reach directly rapidly reaches a ceiling. A quick evolution towards 'narrowcasting' is unavoidable when a transmission chain reaches a certain length.

In even more cases, heavy broadcasting will be present, but it will not be sufficient for some individuals to come into contact with most participants in the chain. With all his prestige, his connections and the diffusive power of the printing press, Erasmus' influence on European manners got diluted with time. This puts a limit on models of cultural diffusion that stress the impact of well-connected or prestigious individuals, imitated 
by their followers, for cultural transmission. Such individuals no doubt exist and, on a short timescale, they are indeed influential. There is a dilemma, though: the ideas that these individuals propagate either owe their success to their intrinsic interest, or to the prestige of the well-connected. If their success is explained by their intrinsic properties, they will no doubt enjoy a competitive advantage, with a little help from their prestigious propagandist, in longer transmission chains. In that case, leader influence can only enhance the success that the idea would have enjoyed anyway, because of its intrinsic interest. On the other hand, if it is entirely arbitrary and explained by leader influence alone, then it will not survive through a long transmission chain, unless that chain is very broad. One might answer that social groups can conserve local arbitrary traditions for quite a long time, for instance as a result of conformism. But long chains of cultural transmission typically span several societies (not only for technologies, but also for major political, legal and religious innovations). Local conservation of arbitrary traditions, since it is arbitrary, will differ for each society, and hence be averaged out as the chain grow long (if it is also narrow enough for each society to feed the chain).

The local impact of social influences, spectacular as it may seem when short scales are observed, is not necessarily scalable at the level of long diffusion chains. On other scales, models stressing local social influences may be more appropriate than models based on psychological hypotheses.

\section{Long and narrow chains as windows to the human mind}

Cultural learners are choosy. They don't learn, adopt, endorse or produce cultural ideas at random, nor is their choice driven by deference or conformity alone. Among the factors that determine their choices, some are idiosyncratic, some are shared with others, some are as good as universal. Cultural epidemiologists are interested in the mental mechanisms that consistently orient cultural choices in roughly everyone. Yet being cognitively attractive does not, by itself, make a cultural item successful. For that to happen, culture must be able to travel long, narrow chains of cultural transmission.

When such chains can be observed to work, they teach us a lot about the human mind in its most general aspects. Think of the population of American students tested in an average psychological experiment: so few people, so uniform, so similar from one experiment to the other, so far removed from the rest of humanity in so many respects (Henrich et al. 20I0). Now consider all the individuals feeding a long and narrow 
cultural transmission chain: so many people, from so many times and places, from so many stages of life and situations - so representative a sample of mankind! When an idea travels through these thousands, millions of different heads, it passes through as many millions of psychological filters, all different, yet with a small cluster of features in common. Along the chain, idiosyncratic and local features all pull in different, inconsistent directions: their effects will be averaged out as the chain grows longer. On the other hand, reliable and consistent features will show clearly through the chain, idiosyncratic features being washed out. Culture transmitted in this way will bear the mark of general structures of the human mind: psychology drives culture, when culture travels long and narrow chains. But not all cultural things come from such chains, and we cannot treat culture as a mere reflection of the human mind - which is why we need to combine predictions derived from psychology with insights derived from the social sciences and the humanities.

\section{References}

Atran, S. 2003. Théorie cognitive de la culture. Une alternative évolutionniste à la sociobiologie et à la sélection collective. L'Homme 166: I07-I44.

Atran, S. 200I.The trouble with memes: Inference versus imitation in cultural creation. Human Nature 124:35I-38I.

Aunger, R. 1999. Against Idealism/Contra consensus. Current Anthropology 40: 93-II5.

Bentley R.A., Lipo C.P., Herzog H.A., and Hahn M.W. 2007. Regular rates of popular culture change reflect random copying. Evolution and Human Behavior 28: 151 - 158.

Boyd, R. \& P. Richerson, 1985. Culture and the evolutionary process. Chicago:The University of Chicago Press.

Boyer, P. 200I. Religion explained: the evolutionary origins of religious thought. New York:

Basic Books.

Boyer, P. 2000. Evolutionary psychology and cultural transmission. American Behavioral Scientist 43: 987 - 1000.

Boyer, P. 1988. Barricades mystérieuses et pièges à pensée: introduction à l'analyse des épopées Fang. Paris, Société d'ethnologie.

Caplan, N. 1965. Puritan Names and the roots of nonconformity. Transactions of the Congregational Historical Society, 20(I), Toronto, 1965. 
Claidière, N. and Sperber, D., 2010. Imitation explains the propagation, not the stability of animal culture. Proceedings of the Royal Society B: Biological Sciences. 277: 65I-659.

Elias, N. [1939] 2000. The Civilizing Process, Vol.I.The History of Manners. Oxford, Blackwell.

Fisher, D.H. 1989. Albion's Seeds : Four British Folkways in America. Oxford, Oxford Univeristy Press.

Haidt J. 2004. The emotional dog gets mistaken for a possum. Review of General Psychology 84: 283-290.

Henrich, J., Heine, S.J., and Norenzayan, A. 2010. The weirdest people in the world, Behavioral and Brain Sciences 33: $61-135$.

Hirschfeld, L. 1997. Why don't anthropologists like children? American Anthropologist I042: 6I I-627.

Hocart, A.M. 1927. Are Savages Custom-Bound? Man 27: 220-221.

Hosbawm, E. and Ranger,T., eds. 1992. The invention of tradition. Cambridge, Cambridge University Press.

Keesing, R. 1982. Kwaio Religion:The Living And The Dead In A Solomon Islands Society. Columbia University Press.

Mesoudi, A. and Whiten, A. 2008. The multiple roles of cultural transmission experiments in understanding human cultural evolution. Phil.Trans. R. Soc. B 363: 3489-350I.

Morin, O. 2010. "Pourquoi les enfants ont-ils des traditions ?" Terrain n55, pp. 10-27.

Nichols, S. 2002. On the Genealogy of Norms: A Case for the Role of Emotion in Cultural Evolution. Philosophy of Science 692: 234-255.

Opie,I. and Opie P. 1959. The Lore and Language of Schoolchildren. Oxford: Oxford University Press.

Richerson, P., \& Boyd, R. (2005), Not by Genes Alone, Chicago:The University of Chicago Press.

Rozin P., Haidt J., and McCauley C.R. 2000. Disgust. In Handbook of emotions, second edition, ed. M. Lewis and J. M. Haviland-Jones, 637-653. New York: Guilford Press.

Rozin, P. and Nemeroff, C.J. 1990. The laws of sympathetic magic: A psychological analysis of similarity and contagion. In Cultural Psychology: Essays on comparative human development, ed. J. Stigler, G. Herdt and R.A. Shweder, $205-232$. Cambridge: Cambridge University Press.

Rubin, D. 1995. Memory in Oral Traditions: the cognitive psychology of epics, ballads and counting-out rhymes. Oxford: Oxford University Press.

Samuelson, S. 1980. The Cooties Complex. Western Folklore 363: 198-210.

Sibree, J. I 883. The Oratory, Songs, Folktales and Legend of the Malagasy. Folk-Lore Journal I: 97.

Sperber, D. and Hirschfeld, L. 2004. The cognitive foundations of cultural stability and diversity. Trends in Cognitive Sciences 8I: 40-46.

Sperber, D. 1997. Explaining Culture :A Naturalistic Approach. Oxford, Blackwell.

Tomasello, M. (1999), The Cultural Origins of Human Cognition, Cambridge, Harvard University Press.

Whiten A. and Mesoudi A. 2009. Establishing an experimental science of culture: animal social diffusion experiments. Phil.Trans. R. Soc. B 363: 3477-3488. 